\title{
Interaction of In-Group Archetypes and Hierarchy while Forming in-Group Community
}

\author{
Yuri V. Gritskov* and Denis V. Lvov \\ Siberian Federal University \\ 79 Svobodny, Krasnoyarsk, 660041, Russia
}

Received 28.07.2015, received in revised form 20.08.2015, accepted 19.09.2015

In this article the interaction of corporate and hierarchy archetypes in the process of forming a group community is considered. The authors point out some emerging contradictions in this process.

Keywords: archetype, the self, hierarchy, corporativity, identity.

DOI: 10.17516/1997-1370-2015-8-11-2325-2330.

Research area: philosophie.

Throughout almost the entire history of mankind deep basic structures of forming a single space of a particular social group have been considered from a wide variety of standpoints. The researchers have raised and highlighted such aspects of the issue as a symbolic and cultural space, group identity, common historical experience, economic conditions, etc.

By the $20^{\text {th }}$ century the development of such "human sciences" like psychology and sociology had given the green light to new approaches to understand the nature of the mechanisms of forming methods of social interaction. Then the theory of the unconscious proposed by S. Freud radically changed the idea of the foundation of human activity.

At the same time exploring the phenomenon of the collective unconscious has turned to be much more difficult than the individual unconscious. The total logic of C. G. Jung's reasoning may imply that he understood the archetypes as inherited from previous generations and enshrined in the collective unconscious schemes, which reflect in the individual consciousness the phenomena and situations, typical for the social and cultural reality. Formation of such schemes is the result of accumulation in the genetic memory of centuries-long collective experience in similarly structured interactions, which a person gets in their lifetime (for example, the adoption of a new member in the community, recognition of their place in the hierarchy, conflict and so forth).

Existential images, which appear after the imposition of unconscious schemes to social situations, determine the activation of the relevant (a priori) response programs. In this sense, an archetype can be defined as

(C) Siberian Federal University. All rights reserved

* Corresponding author E-mail address: grickov50@mail.ru 
a "program" of the collective unconscious, constituting the individual's perception of phenomena in social reality, and through this perception - determining the individual's social behavior. The archetype does not prescribe details, but rather sets the general scheme of the perception of social phenomena and acts as a structure-forming factor in the area of social interactions (See more on structure-forming role of archetypes in [Vasil'kova, p. 376]. Thus, the archetypes themselves are neither representations nor behavior, although they are manifested in these phenomena.

The archetypal programs of social behavior are extremely conservative by their nature, they operate independently of rationally constructed programs that regulate social interactions through legislation, regulations, codes, etc. Time-tested and conservative reliability of the archetypal program insures the society against destructive adventures of the collective consciousness, that can be too risky, often fraught with irreversible consequences. For example, the moral imperative generated by the archetypal program is often opposed to the imperatives of rational law obedience and expediency.

The archetypal programs of the collective unconscious may be called "social instincts" set the behavioral responses of the individual via creating an existential image of a social situation "following" the relevant prototype [Gritskov, 2004, p. 19-24]. In this context, an archetype can be defined as preceding to experience knowledge about the object, and the archetypal image can be defined as a result of "merging" of preceding to experience "archetype" with the knowledge obtained in the process of experiential interaction with the object. Thus, the situation is perceived through the prism of an archetypal image and becomes the "human situation", which activates both the experience of previous generations kept in the unconscious collective and an individual experience of the subject immersed in a particular social situation.

In our view, the concept of archetypes as a social instinct enhances the research opportunities for the collective unconscious: while C.G. Yung described mainly schemes for constructing existential images of subjects in a social reality (a warrior, a wise old man, a hero, Anima, etc.), we turn attention to the schemes of the existential images of typical human situations (selfidentification, incorporation into the hierarchy, some sorts of wine, game, holiday, friendship and enmity), ways of mastering which determine the content of any culture.

However, there are many situations in the social reality that cannot be unambiguously identified by the collective unconscious. In such cases, the archetypal program may construct an inconsistent existential image, creating the effect of "circular firing squad". As a result, there is no complete image of what is happening, which would activate the corresponding program of the archetypal behavior. Thus, structureforming and "world regulating" (a term by V.V. Vasil'kova) archetypal functions are not realized, so that the subjects experience a strong existential discomfort, prompting them to intense reflection.

Let us consider the interaction of such programs on the example of corporate and hierarchy archetypes.

\section{Archetype of corporativity}

Constituted by the Self archetype of an existential image, or experience of alienation from the outside world ("the Self in the world") puts a person in a situation of existential loneliness, a tragic situation described by E. Fromm: "while a man used to be an integral part of the world, he/ she was not aware of any possibilities or effects of individual actions, and he/she did not have to 
be afraid of the world. However, becoming an individual, he/she is left alone with the world, which is so stunning and frightening" [Fromm, p. 15]. Note that this very situation generates questions, which require philosophical reflection (about the origin of the universe, the "place" of a person in it, the meaning of life, etc.).

Realizing the personal detachment from the world, a person cannot return to the blissful state of unconscious unity with it. The situation is aggravated by the fact that the world has to be confronted single-handed. But this very situation leads to the desire of the Self to break out beyond itself, to connect with other, more powerful Self, to confront a hostile world and "alien" selves with this Self. Hence, the archetype of the Self produces the need for existential communion with others. It is vital for a person to identify themselves with any community.

Therefore the archetypal program of the Self is present in any social community, e.g. a family, a religious community or a commercial organization. Under this program, every community is perceived by its members (I-Self) as isolated from the world, or an integral and unique We-Self.

In relation to this the existential interaction of the individual with the community can be understood as an interaction of I-Self with the We-Self, which may be linked to each other either in harmony or in discord. Obviously the appearance of the individual in the existential space of the collective Self is associated with the transformation of his/her own Self. An example of such a transformation of I-Self is noted by E. Durkheim religious sanctification of man's relationship to society. Another example is that feeling a part of socio-cultural community, people unconsciously seeks to act as its representatives.

As it was already mentioned, one can fully realize himself or herself only in conjunction with the members of "his/her" social community (We-Self). In connection with this there is a task of distinguishing "us" from "them". However, as noted by A.I. Fet [Fet], common to all higher animals "social instinct", which allows distinguishing between "us" and "them" found a "global" realization among people. This means that the person identifies "his/her own people" not in line with instinctual (genetically inherited) program settings, but rather in accordance with the inherited cultural markers, indicated in the traditions. That is the instinctive program of recognition other people as "our own" is still incomplete and a man cannot exist without cultural content.

An archetypal program constituting a situation of "we and others" can be called the archetype of corporativity. The archetype of corporativity opens the possibility of individual perception of themselves as a part of the sociocultural community, and the world perception through the prism of belonging to this community. Relationships with individuals who are identified as "our own" are created by the standards of "most favored option", and the relationship with the "other" are made the contrary way.

\section{Archetype of Hierarchy}

As shown above, the archetype of the Self governs the formation of the basic ideas about the world and building a relationship with it. Within the community, a person is faced with the task of determining their own place and possible limits of their actions. If you recall the concept of the Self by G.H. Mead, that part of the human personality, which he refers to as "Me", allows a person to create a certain understanding of himself/herself as a member of the community. "Me" is an image of himself/herself in the manifold relationships with other members of the community. This image is based on an understanding of the individual's own position in the community and 
the expectations of the other members of the community, corresponding to their positions.

According to V. Chalidze, "the hierarchical structure appears in any group of interacting people" [Chalidze, p. 58]. Moreover, the definition of an individual's position in the hierarchy happens almost unconsciously, "automatically". "This assessment is provided automatically, which allows each individual to define a hierarchy of wills in the community and their place in the hierarchy through successive comparisons of their wills to the will of other individuals (i.e., to set a number of hierarchical relations)" [Chalidze, p. 29].

We state that the archetype of hierarchy is a program of the collective unconscious, which creates the image of any social community as a "pyramid" of unequal levels. Social interactions within this hierarchically community are ambivalent, at the same time they "have the desire to rule and the willingness to obey the rule, aggression (regarding both a superior and a subordinate) and willingness to cooperate, hostility and sympathy" [Gritskov, 2006, p. 87].

The archetype of hierarchy governs the relationship of individuals and groups within the social pyramid. First, individuals tend to occupy a possible higher place in the hierarchy. Secondly, representatives of each of the levels use a part of the living resources of the lower levels' representatives, and delegate a part of their life resource to the representatives at a higher level (if there is any) in exchange for patronage and protection. As a result of this archetype the community is ordered (structured), and its members are able to optimize their participation in the being of the collective integrity.

\section{Contradictions between archetypes of corporativity and hierarchy}

The archetypal programs of corporativity and hierarchy can work for the integrity and stability of the community together and effectively only if the hierarchical signs, which set the rankings in the group, are selected in accordance with such meanings and values, which We-community recognizes as its own. In this collective whole the archetype of corporativity will cultivate a sense of community and equal belonging to "their own" social group, while the archetype of hierarchy realizes the ordering of the positions and interactions within the group integrity. Otherwise there may be an existential conflict between produced by the archetype of corporativity a desire for equality and unity and produced by the archetype of hierarchy a desire for orderly interactions within the organizational unity.

In addition, the contradictions between the archetypal programs of corporativity and hierarchy may arise due to the fact that the hierarchical structure in itself produces its own significant symptoms, independent of the values and meanings, formed by the archetypal program of corporativity. First of all, among these signs there is a power as the ability and opportunity to carry out one's will. With regard to internal corporate relations, this means that the person in power can ignore the interests of community and use a subordinate as its own resource. In such a relationship there is no existential sense of unity between the ruling and obeying anymore, they are perceived as unfair, jeopardizing the integrity of the group. Many hierarchical organizations tend to the impersonal relationship structure where each person perceives themselves and the other, not as I-Self, representing the collective we-Self, but as an individual's social role with a certain set of expected responses. Along with it one of the most important aspects of human relations is compliance with specified standards of behavior set by their social position, contrary to achievement of a harmonic unity in the 
collective whole of unique individuals, who recognize the right of each other to be unique.

In turn, the archetype of corporativity requires either overt or covert adjustment of individual values and meanings to some generalized scheme. In this consideration, it can be argued that conformism as a socio-cultural phenomenon emerges due to the work of archetypal program of corporativity. So a person can take the point of view of the group only in order to be included in the group legitimately, especially if his/her fundamental interests are not affected. A situation when the individual takes a decision imposed by a group upon him/her in fear of being ostracized is also quite possible (and it would be supported by the archetype of corporativity). Hereby, the archetype of corporativity could lead not only to a voluntary unity of free men who share a common vision, but also to forced restrictions to them as Selves. To make We-Self viable the existential comfort from belonging to it should significantly exceed the conformist costs of its members (individual Selves). Otherwise, there is an increased risk of weakening the unity and separating within the corporation of dissident Selves, which demonstrate the values and behaviors that are contrary to generally accepted in the community.

These dissident Selves ("strangers among us") are potentially a source of acute internal corporate conflicts, as We-Selves tend to take them more belligerently than "strangers". After all, while it is natural when one does not trust the actions of outsiders (this distrust is "legitimized" by their status of "alien Selves"), it is as natural to trust your "own" members, and this trust should be justified by "our own members" by loyalty not only to the world view and the core values within the group, but also to the existing hierarchy in the group. Dissident blows the group's Self from inside, which has not been expect from him/her and that is directly contrary to his/her role of "our own". Failure of "loyalty expectations" creates preconditions for the perception of the member (or a part of) the group as a "traitor", while he/ she is only trying to restore harmony between the archetypal programs of corporativity and hierarchy. But the renegade is already deprived of any internal privileges and is ostracized; now it is forbidden to him/her to publicly identify with the group and this person is divested of all previously assigned to him/her social roles (for example, in Christianity the excommunication from the community and existential comfort that allows staying in it is considered one of the most serious penalties). In fact, such a violent interruption of communication between the community and the individual is an execution causing the death of social I-Self by We-Self.

Shown contradictions generated by archetypes of corporativity and hierarchy can become the basis both for the destruction and for the development of the unity of the group, the group as a whole and of its individual representatives. On the one hand, a clear dissonance between the archetypal programs can lead to a complete imbalance of intragroup relations with farreaching consequences - up to split into several parts (and potentially independent groups), or simple group disintegration. On the other hand, the constructive resolution of such a deep conflict may result in a qualitative change (the adaptation as an option) of the group structure and its core values.

\section{References}

Chalidze, V. Ierarkhicheskii chelovek [The hierarchical person]. Moscow, Terra, 1991. 224 p.

Fet, A.I. Instinkt $i$ sotsial'noe povedenie [Instinct and social behavior]. Novosibirsk, Sova, 2005, pp. 25-46. 
Fromm, E. Begstvo ot svobody [Escape from freedom]. Moscow, Academic Project, 2007. 272 p.

Gritskov, Iu.V. Fenomen stradaniia i sposoby ego osvoeniia v kul'ture [The phenomenon of suffering and ways of its learning in culture]. Dissertation of Doctor of Philosophical Sciences. Omsk, 2006, $321 \mathrm{p}$.

Gritskov, Iu.V. Obrazy stradaniia v stradaiushchem soznanii [The images of suffering in suffering consciousness]. Krasnoyarsk, 2004, 120 p.

Vasil'kova, V.V. Poriadok i khaos v razvitii sotsial'nykh sistem [Order and chaos in the development of social systems]. Saint-Petersburg, Lan', 1999, 480 p.

\section{Взаимодействие архетипов корпоративности \\ и иерархии в процессе становления \\ внутригрупповой общности}

Ю.В. Грицков, Д.В. Львов

Сибирский федеральный университет

Россия, 660041, Красноярск, пр. Свободный, 79

В статье рассматривается взаимодействие архетипов корпоративности и иерархии в процессе становления групповой общности. Исследуются возникающие в этом процессе противоречия.

Ключевые слова: архетип, самость, иерархия, корпоративность, идентичность.

Научная специильность: 09.00.00. - философские науки. 